\title{
Laparoscopic cholecystectomy in an adult with agenesis of right hemidiaphragm and limb reduction defects: First report in literature
}

\author{
Julide Sagiroglu, ${ }^{1}$ Ercument Tombalak, ${ }^{1}$ Sarenur Basaran Yilmaz, ${ }^{2}$ \\ Fikret Balyemez, ${ }^{3}$ Tunc Eren, ${ }^{1}$ Orhan Alimoglu ${ }^{1}$ \\ ${ }^{1}$ Department of General Surgery, Istanbul Medeniyet University Faculty of Medicine, Istanbul, Turkey \\ 2Department of Medical Genetics, Istanbul Medeniyet University Faculty of Medicine, Istanbul, Turkey \\ ${ }^{3}$ Department of Radiology, Istanbul Medeniyet University Faculty of Medicine, Istanbul, Turkey
}

\begin{abstract}
The importance of the complete absence of a hemidiaphragm or unilateral diaphragmatic agenesis in adulthood in relation to performing laparoscopic procedures has not been well documented. This article reports for the first time in literature a case of successful laparoscopic cholecystectomy in an adult with previously undiagnosed unilateral diaphragmatic agenesis. A 36-year-old female complaining of stubborn right upper abdominal pain radiating to her upper back was diagnosed as having cholelithiasis and was scheduled for laparoscopic cholecystectomy. There were also bilateral upper extremity malformations to a certain level. Routine diagnostic tests demonstrated that her entire liver and some bowel loops were in the right hemithorax, suggesting right-sided diaphragmatic hernia. Laparoscopic procedure was performed with the insertion of four trocars. Exploration of abdomen revealed total absence of the right hemidiaphragm. Cholecystectomy was completed laparoscopically in about 45 minutes without need for additional trocars. Patient had an uneventful recovery and was discharged on the second postoperative day without any complaint. Laparoscopic cholecystectomy in adults with diaphragmatic agenesis and intrathoracic abdominal viscera can be performed successfully. Nevertheless, any bile duct aberrations must be documented prior to surgery, and the surgeon should be able to convert to open procedure if necessary.
\end{abstract}

Keywords: Agenesis; cholecystectomy; diaphragm; laparoscopic; unilateral.

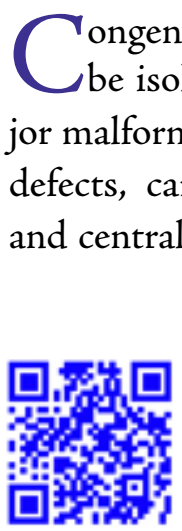


precluding cholecystectomy has been reported [2]. The present case is that of an adult patient with previously unknown unilateral DA who underwent laparoscopic cholecystectomy.

\section{CASE REPORT}

A 36-year-old female presented with a 1-year history of progressive dyspepsia and right upper quadrant (RUQ) pain radiating to right upper back. Since early childhood she had never had a good night's sleep without a pile of four pillows. The patient also had remarkable congenital upper extremity malformations, such as limited elbow joint mobility, fifth finger clinodactyly, a short fifth metacarpal bone on the right, and a short left forearm with only 3 fingers. The patient was the fifth child of non-consanguineous, healthy parents and she had given birth to 2 healthy children through normal delivery. Her perinatal history was unremarkable.

Radiographs showed mild lumbar scoliosis, nonvisualized first and second metacarpal bones and fingers on the left hand; very small, triangular-shaped third interphalangeal bone; short and bowed left radius and ulna; and radio-humeral synostosis on the left. Physical examination also revealed diminished breath sounds and dullness upon percussion to the right pulmonary base. All laboratory parameters and liver function tests were normal. Chest $\mathrm{x}$-ray suggested a right diaphragmatic hernia (Figure 1). Abdominal ultrasound and computed tomography (CT) confirmed right diaphragmatic herniation of abdominal viscera and elevated gallbladder with a bile stone of $9 \mathrm{~mm}$ (Figures 2, 3). Left medial segment and right lobe of the liver were athrophic, lateral segment of the left lobe and caudate lobe were hyperthrophic. Magnetic resonance choledochopancreatography (MRCP) confirmed normal intrahepatic and extrahepatic bile ducts (Figure 4).

After $\mathrm{CO}_{2}$ insufflation of the abdomen to 12 $\mathrm{mmHg}$, trocars were inserted through the umbilicus for the camera, subxyphoid and two paraumbilical working ports. Laparoscopy revealed right hemidiaphragm agenesis with an intra-thoracic liver. Bowel loops and omentum were partially in the

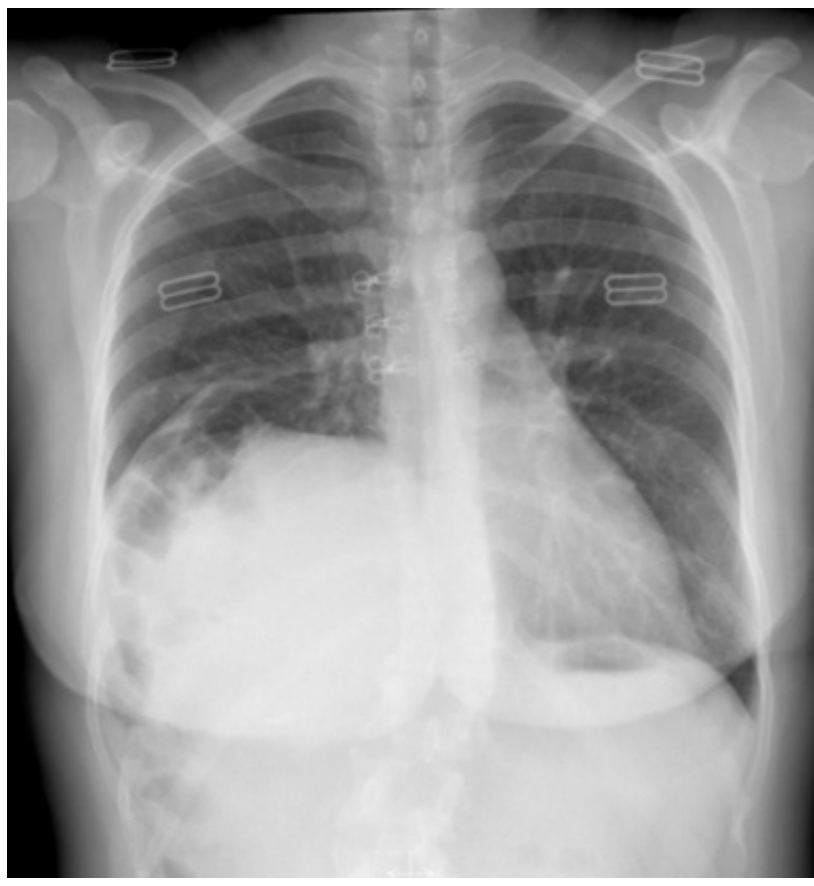

FIGURE 1. Postanterior (PA) chest x-ray

right hemithorax. Central tendon of the diaphragm was absent. Gallbladder was elevated and the tip of the fundus had a slight posterolateral rotation. Cholecystectomy was completed laparoscopically in about 45 minutes without the need for additional trocars. Patient was discharged on the second postoperative day without any complaint.

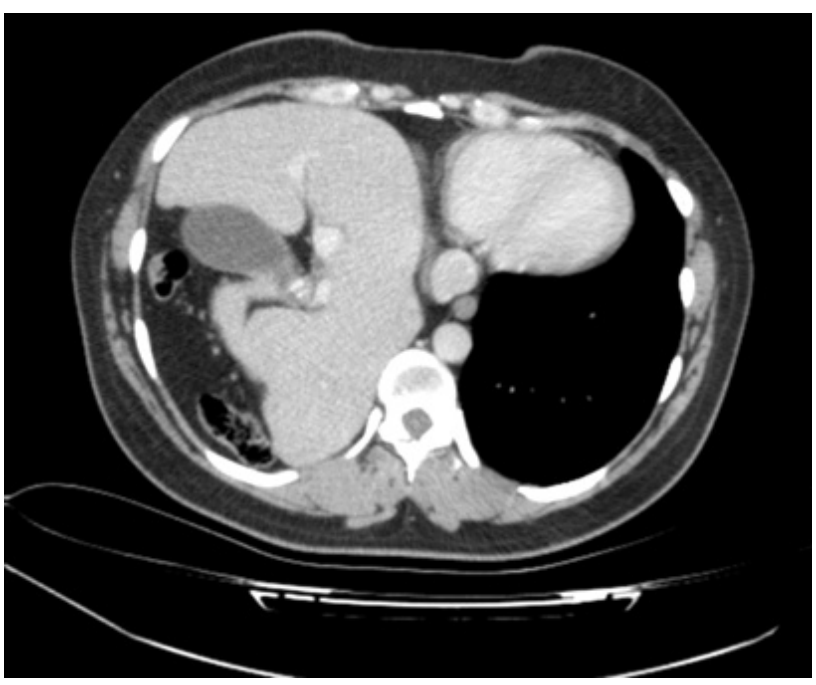

FIGURE 2. Computed tomography (CT), axial view 


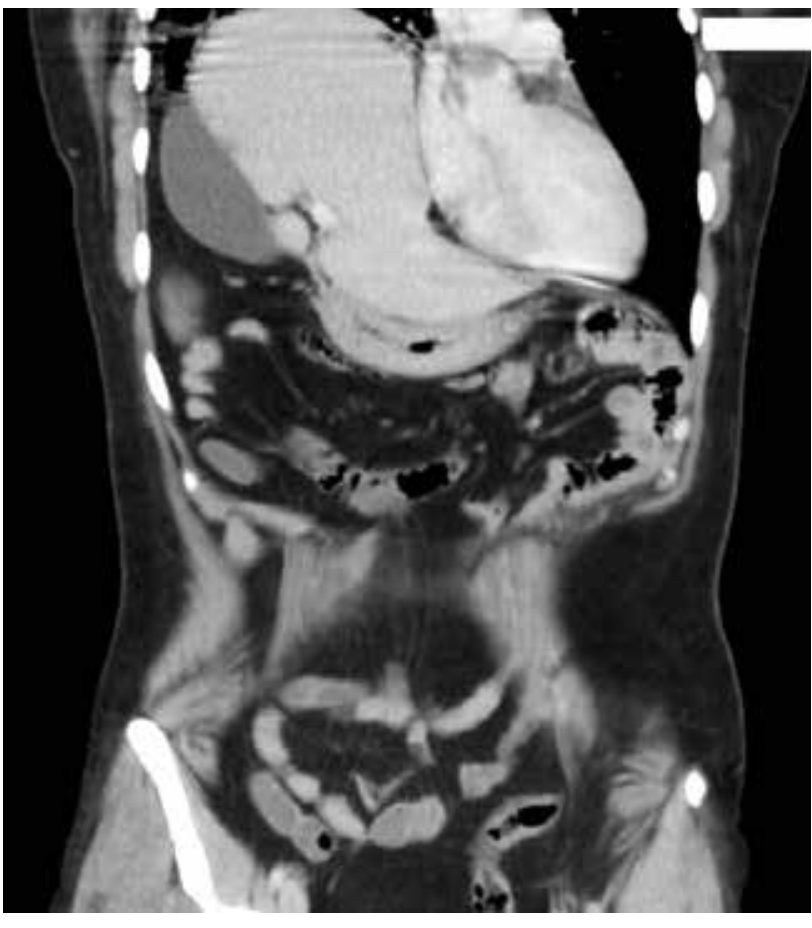

FIGURE 3. Computed tomography (CT), coronal view

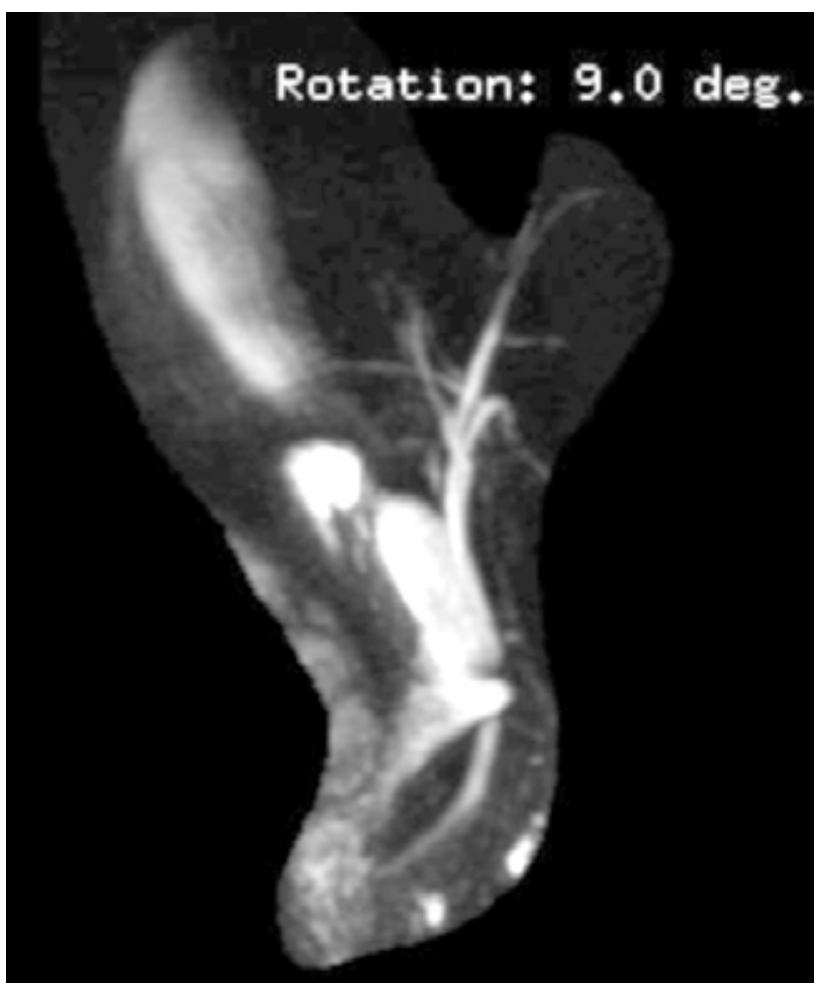

FIGURE 4. Magnetic resonance choledocho-pancreatography (MRCP)
On the eighth follow-up week, she was referred to the medical genetics clinic for mutational analysis. Chromosome analysis revealed a $46, \mathrm{XX}$, normal karyotype and a C677T heterozygous mutation of MTHFR gene. Echocardiogram was normal.

\section{DISCUSSION}

Agenesis of hemidiaphragm is exceedingly rare in adults. In literature, 9 previous case reports of this condition in adults have been published $[3,4]$.

Bingham first described DA in 1959 as a distinct entity from the more common Bochdalek-type of posterolateral congenital diaphragmatic defect [5]. The incidence of DA is reportedly $27-31 \%$ of cases of congenital diaphragmatic hernia. Additional information on the management of neonatal DA has enabled better survival. The incidence of adults with DA is likely to increase in the future due to the higher survival rates of neonates.

Diagnosis of DA in adults is based on a high index of clinical suspicion as well as imaging studies. Dullness upon percussion, and absent or diminished breath sounds in a lung field may indicate congenital diaphragmatic hernia. Imaging studies (chest radiography and abdominal ultrasound) are confirmatory. In adults with DA presenting with cardiorespiratory or gastrointestinal symptoms, the main principle of diagnosis should be systematic investigation of the gastrointestinal tract to rule out pathology in the herniated intrathoracic viscera.

Incidence of bile stones has not been clearly defined in adults with DA. There is 1 former case report in literature presenting an adult with bile stones who had previously unknown right-sided DA [1]. Wakai et al. preferred non-surgical management of cholecystocholedocholithiasis for this patient. Abdominal ultrasound revealed dilatation of intra and extra-hepatic bile ducts suggestive of choledocholithiasis. Gallbladder was not visualized during laparoscopy, which precluded laparoscopic cholecystectomy. Endoscopic retrograde cholangiopancreatography (ERCP) confirmed common bile duct dilatation with choledocholithiasis. The patient had no other co-morbid medical condition, so they decided on conservative management. 
ERCP with endoscopic sphincterotomy, stone extraction, and stenting of the common bile duct were performed. Following ERCP, gallstone dissolution therapy was initiated.

In the present case, gallbladder and extrahepatic bile ducts were very well visualized both preoperatively and intraoperatively, which enabled completion of the operation laparoscopically. Liver and gallbladder were elevated, and the tip of the gallbladder fundus showed slight posterolateral rotation. Cholecystectomy was completed laparoscopically within 45 minutes and additional trocars were not needed.

Limb reduction defects are one of the most common concomitant conditions with $10 \%$ ratio in non-syndromic congenital diaphragmatic hernia [6]. Co-existence of limb reduction defects and congenital diaphragmatic hernia is thought to be the result of an abnormality in developmental genes that are especially active in the early embryonic stage when limb formation and diaphragm development overlap $[6,7]$. In addition to genetic factors, some teratogen exposure is considered to be responsible for this state, such as Vitamin A deficiency or any disruption of the retinoic acid pathway [8]. Though there are reports about a genetic basis for congenital diaphragmatic hernia, it is still uncertain.

In the presented case, clinical findings did not fit into any known single gene disorder with congenital diaphragmatic hernia, including Fryns syndrome, Smith-Lemli-Opitz syndrome, Brachman de Lange syndrome, CHARGE syndrome, Goldenhar syndrome, Beckwith-Wiedeman syndrome, Marfan syndrome, Noonan syndrome, Spondylocostal Dysostosis syndrome, Simpson-Golabi-Behmel syndrome, and Fraser syndrome. Presence of both congenital diaphragmatic hernia and limb reduction defects was accepted as a co-existence with an unidentified genetic basis or a novel syndrome in this case.

In adults with DA, laparoscopic cholecystectomy can be performed successfully. Nevertheless, bile duct aberrations must be documented prior to surgery, and the surgeon should be able to convert to open procedure if necessary. Emphasis can be placed on conservative management, followed by gallstone dissolution therapy when laparoscopy fails to provide adequate visualization of the gallbladder and the ductal system.

Acknowledgements: Authors are thankful to all medical and surgical staff of the faculty.

Conflict of Interest: None declared.

Financial Disclosure: The authors declared that this study has received no financial support.

Authorship contributions: Concept - J.S.; Design - J.S.; Supervision - J.S., T.E., O.A.; Funding - All authors; Materials - J.S., E.T., F.B.; Data collection \&/or processing - J.S., E.T., S.B.Y., F.B.; Analysis and/or interpretation - J.S., S.B.Y.; Literature search - J.S., E.T., S.B.Y.; Writing - J.S., S.B.Y.; Critical review - O.A., T.E.

\section{REFERENCES}

1. Slavotinek AM, Warmerdam B, Lin AE, Shaw GM. Populationbased analysis of left- and right-sided diaphragmatic hernias demonstrates different frequencies of selected additional anomalies. Am J Med Genet A 2007;143A:3127-36. Crossref

2. Wakai A, Winter DC, O'Sullivan GC. Unilateral diaphragmatic agenesis precluding laparoscopic cholecystectomy. JSLS 2000;4:259-61.

3. Passarge E, Halsey H, German J. Unilateral agenesis of the diaphragm. Humangenetik 1968;5:226-30. Crossref

4. Gibbs DL, Rice HE, Farrell JA, Adzick NS, Harrison MR. Familial diaphragmatic agenesis: an autosomal-recessive syndrome with a poor prognosis. J Pediatr Surg 1997;32:366-8. Crossref

5. Bingham JAW. Herniation through congenital diaphragmatic hernia defects. Br J Surg 1959;47:1-15. Crossref

6. van Dooren MF, Brooks AS, Tibboel D, Torfs CP. Association of congenital diaphragmatic hernia with limb-reduction defects. Birth Defects Res A Clin Mol Teratol 2003;67:578-84. Crossref

7. Bhan V, Rajagopal P, Kumar K, Raghavendra KH. Agenesis of the hemidiaphragm: a rare presentation in an adult. Indian J Chest Dis Allied Sci 2013;55:109-11.

8. Macayran JF, Doroshow RW, Phillips J, Sinow RM, Furst BA, Smith LM, et al. PAGOD syndrome: eighth case and comparison to animal models of congenital vitamin A deficiency. Am J Med Genet 2002;108:229-34. Crossref 